\title{
EUTOMIA
}

Revista de Literatura e Linguística

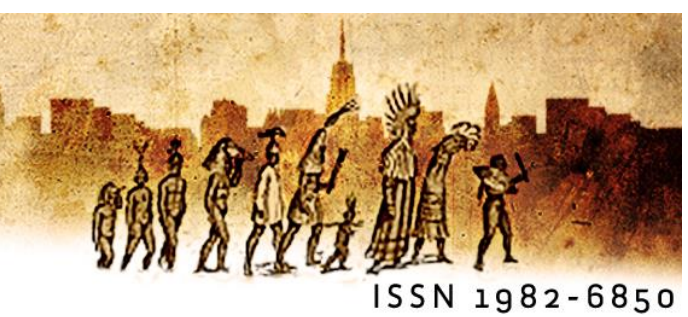

\section{Atualização e relações interativas: situações favorecedoras do desenvolvimento profissional do tecnólogo-professor iniciante}

\section{Improve and interactive relations: situations that support the professional development of the technologist- beginner teacher}

Laura Maria Andrade de Sousa' (UFPI)

Maria da Glória Carvalho Mouraii (UFPI)

\begin{abstract}
Resumo: O presente artigo é fruto de recorte de uma investigação sobre a formação e o desenvolvimento profissional dos tecnólogos-professores em início de carreira na Educação Profissional, desenvolvida durante o mestrado no Programa de Pós-Graduação em Educação da Universidade Federal do Piauí. Em termos metodológicos, configura-se como uma pesquisa de abordagem qualitativa, que tem como objetivo geral analisar as situações que contribuem para o desenvolvimento profissional do tecnólogo-professor em início de carreira. De modo específico, buscouse: Identificar as situações consideradas relevantes pelo tecnólogoprofessor para seu desenvolvimento profissional docente e compreender o processo de construção do desenvolvimento profissional do tecnólogoprofessor. Para sua realização, colaboraram seis tecnólogosprofessores que atuam em campi de um Instituto Federal de Educação. Os dados foram organizados em torno de duas categorias analíticas e interpretadoscom base na Análise de Discurso (AD) francesa e em pesquisadores dessa temática. Os resultados apontam que a relação com os pares mais experientes e com os alunos são os principais elementos que contribuem para a consolidação da aprendizagem da docência e do desenvolvimento profissional dos tecnólogos-professores iniciantes. Concluímos que há necessidade de acompanhamento e apoio da coordenação pedagógica e estreitamento das relações institucionais entre departamentos e coordenações.

Palavras-chave: Desenvolvimento Profissional; Iniciação à Docência; Tecnólogo-Professor; Educação Profissional.
\end{abstract}




\begin{abstract}
This article is the result of an investigation of the training and professional development of technologists-teachers at the beginning of their careers in Professional Education, developed during the master's degree in the Postgraduate Program in Education, from the Federal University of Piauí. In methodological terms, it is configured as a qualitative research, whose general objective was to analyze the situations that contribute to the professional development of the technologistteacher at the beginning of his career. Specifically, it sought to: Identify the situations considered relevant by the teacher technologist for his professional teaching development and understand the process of construction of the professional development of the teacher technologist. Six technologists-teachers who work on campuses at the Federal Institute of Education collaborated for its realization. Data were organized around two analytical categories and interpreted based on the French Discourse Analysis. The results show that the relationship with the most experienced peers and with the students are the main elements that contribute to the consolidation of teaching learning and the professional development of beginning technologists-teachers. We conclude that there is a need to monitor and support pedagogical coordination and to strengthen institutional relations between departments and coordinations.

Keywords: Professional Development; Teaching Initiation; TechnologistTeacher; Professional Education.
\end{abstract}

\title{
Introdução
}

A política de expansão da Educação Profissional, proporcionada pela Lei no 11.892/2008, que também criou os Institutos Federais de Educação, Ciência e Tecnologia IFs a partir dos Centros Federais de Educação Profissional e Tecnológica - CEFETs, Escolas Técnicas e Agrotécnicas Federais, implementada entre os anos 2003 a 2016, mais do que quadruplicou as unidades existentes até 2002, totalizando hoje 647 campi em funcionamento, distribuídos entre os IFs, os CEFETs, as escolas vinculadas às Universidades Federais, o Colégio Pedro II e uma Universidade Tecnológica, que atendem quase um milhão de estudantes nos diversos níveis e formas da EP e da formação de professores, de acordo com os dados da Plataforma Nilo Peçanha (PNP) 2019.

O Instituto Federal de Educação, Ciência e Tecnologia do Piauí (IFPI), em virtude dessa expansão, em seis anos, passou de cinco para vinte campi ampliando o quadro de servidores para atender à demanda de matrículas e à oferta de novos cursos. Entre 2013 e 2018, ingressaram cerca de 600 professores, cuja maioria é bacharel ou tecnólogo com pouca ou nenhuma experiência docente, seja na educação básica ou na educação profissional. Essa lacuna torna-se particularmente relevante nos IFs (mais ainda que nas 
universidades), em razão de metade de sua oferta dá-se no nível médio, conforme prescrito na lei de sua criação.

O IFPI, na tentativa de minimizar o impacto do início da carreira docente dos professores ingressantes desenvolveu um programa de acolhimento a esses profissionais abordando questões gerais, como a missão, o papel, os objetivos e as finalidades dos IF's nos territórios, sua estrutura pluricurricular e multicampi, pesquisa, extensão, níveis e formas de organização da EPT, bem como discutindo os temas de cunho mais pedagógico, tais como: projeto político-pedagógico, projeto pedagógico de curso, avaliação da aprendizagem e as atividades docentes a serem por eles desenvolvidas. Tudo isso intensificou o interesse em realizar essa pesquisa que se abriga no campo da formação de professores e tem como aporte teórico a concepção de formação docente na perspectiva de desenvolvimento profissional, com foco no início da carreira docente dos tecnólogosprofessores que atuam na EP.

Partindo desse pressuposto, a pesquisa busca responder à seguinte questão: Que situações contribuem para o desenvolvimento profissional do tecnólogo-professor? Em busca de respostas para essa questão, definiu-se como objetivo geral: analisar as situações que contribuem para o desenvolvimento profissional do tecnólogo-professor em início de carreira. De modo específico, buscou-se: Identificar as situações consideradas relevantes pelo tecnólogo-professor para seu desenvolvimento profissional docente e compreender o processo de construção do desenvolvimento profissional do tecnólogo-professor.

Metodologicamente, optou-se pela pesquisa de abordagem qualitativa do tipo descritiva, cujo campo foi o Instituto Federal do Piauí (IFPI), sendo que dos 20 campus, selecionaram-se quatro: Teresina Central, Floriano, Oeiras e Valença. A população investigada foi constituída por 22 tecnólogos-professores, dentre o universo de 56, que aderiram à pesquisa e responderam o questionário enviado, instrumento utilizado na primeira etapa da pesquisa. Para a segunda etapa, a entrevista no grupo focal, definiu-se que os participantes seriam em número de seis, representando $10 \%$ do total desses docentes.

No que se refere à estrutura do texto, este artigo está assim organizado: inicialmente se contextualiza o objeto de estudo; em seguida apresenta-se o referencial teórico; a definição do tipo de pesquisa e a caracterização do lócus da investigação, 
interlocutores; as técnicas e os instrumentos de coleta; a organização e interpretação dos dados à luz da análise de discurso (AD); os resultados encontrados no campo empírico e produzidos na investigação, e, por fim, as considerações finais.

\section{Formação e desenvolvimento profissional do tecnólogo-professor}

Neste trabalho, assumimos a formação docente em uma perspectiva mais ampliada conforme a concebe Marcelo (2009), quando afirma que a carreira docente se desenvolve em um movimento que perpassa toda a trajetória do sujeito em direção à aprendizagem profissional como professor, pois concebe o desenvolvimento profissional docente "[...] como um processo, que pode ser individual ou colectivo, [...] que se vai construindo à medida que os docentes ganham experiência, sabedoria e consciência profissional" (MARCELO, 2009, p. 10-11).

Assim, o conceito de desenvolvimento profissional diferencia-se dos demais conceitos como formação contínua, reciclagem, educação em serviço, por superar a visão funcional e pontual de formação do professor, em direção a uma concepção que compreende a formação como fases distintas da carreira nas quais as necessidades formativas dos professores são específicas e diferenciadas.

Desta forma, o desenvolvimento profissional docente, segundo García (1999), apoiado em Feiman-Nemser, tem a seguinte estrutura e características: a pré-formação (fase da escolarização básica); a formação inicial (aquisição dos conhecimentos profissionais); iniciação (o exercício profissional); e a formação permanente (após os cinco anos de atuação como profissional). Daí ser necessário que as instituições de ensino (re)pensem suas práticas de inserção dos professores iniciantes, sob pena de "[...] acentuar nesses primeiros anos de profissão dinâmicas de sobrevivência individual que conduzem necessariamente a um fechamento individualista dos professores", conforme enfatiza Nóvoa (2007, p.13).

As formas de integração dos professores novéis na instituição, ou a falta delas, podem tanto dificultar seu processo de socialização quanto levar ao isolamento e ao desinvestimento na profissão. Cunha (2010) acredita que a despreocupação ou naturalização com que as instituições recebem os professores iniciantes pode ser motivada tanto pelo desconhecimento da importância do exercício da profissão para a consolidação 
da aprendizagem da docência quanto pela crença de que a formação inicial é capaz de oferecer todo o conhecimento profissional necessário para o enfrentamento das situações da prática.

A fase de iniciação à docência é, assim, um período de contradições no decurso da trajetória profissional do professor, pois tanto pode favorecer uma intensa aprendizagem dos conhecimentos, da competência e da cultura profissional quanto pode recrudescer as crenças e valores adquiridos ainda nas fases da escolarização básica e profissional. Nessa etapa do desenvolvimento profissional a atenção e o apoio institucional são imprescindíveis para minimizar as dúvidas e as preocupações que permeiam a prática docente, pois os primeiros "anos de profissão são decisivos na estruturação da prática profissional e podem ocasionar o estabelecimento de rotinas e certezas cristalizadas sobre a atividade de ensino que acompanharão o professor ao longo de sua carreira" (NONO, 2011, p. 19).

A forma como cada professor iniciante vivencia essa fase tem relação com suas características individuais e com os contextos sociais e institucionais nos quais cada um está imerso. No caso dos tecnólogos iniciantes na docência, a postura de reprodução das práticas vivenciadas no período de sua escolarização ou formação profissional pode se tornar mais evidenciada em razão da sua formação de origem e/ou da ausência da experiência profissional anterior.

Os primeiros anos do exercício da profissão são cruciais tanto para a consolidação das aprendizagens do ofício de ensinar quanto para a socialização, a apropriação da cultura e a constituição da identidade profissional. Os estudos têm demonstrado que, além das características pessoais e institucionais, as lacunas da formação inicial podem contribuir para uma inserção profissional dos docentes iniciantes mais ou menos difícil. No entanto, também reconhecem que a docência em função de sua complexidade mesma e da sobrecarga das demandas postas aos professores em virtude das mudanças sociais, econômicas, tecnológicas e culturais ocorridas nas últimas décadas potencializam as dificuldades dos docentes principiantes (MARCELO; VAILLANT, s/d).

Pelo que indicam as pesquisas nacionais (GUARNIERE, 2005; NONO; MIZUKAMI, 2006) e as estrangeiras (GARCÍA, 1999) as principais dificuldades dos docentes iniciantes que atuam na educação básica, são: a preocupação com o aperfeiçoamento e a consciência da insuficiência da formação; o pouco ou nenhum apoio e/ou orientação institucional ao 
desempenho profissional; a falta de domínio dos aspectos didáticos para a organização das atividades de ensino e gestão da classe; a avaliação das aprendizagens dos alunos; o tratamento diferenciado aos alunos com dificuldade de aprendizagem; a relação com pais, comunidade e com os pares.

Além dessas dificuldades resultantes tanto da incompletude da formação quanto da pouca experiência dos professores iniciantes, que não lhes possibilitam os pontos de ancoragem para apoiar e regular sua prática, outro elemento agravante é o isolamento em que vivem os novatos no interior da escola, dados a fragilidade dos laços que mantêm com seus pares, consoante Romanowski e Martins (2013).

Cunha e Zanchet (2010) referem que são poucas as investigações sobre o docente iniciante na educação superior no Brasil e sugerem que o aparente "desinteresse" pela questão dá-se em razão de um pressuposto inquestionável, ratificado por todos: a formação voltada para a pesquisa também o qualifica para o ensino. Para as autoras, a relação pesquisa e ensino não se dá de forma tão linear quanto aparenta e são necessárias outras mediações para que ela aconteça.

Também na Educação Profissional ainda é frequente a ideia de que, para ser professor nessa modalidade de ensino, basta o conhecimento técnico da(s) disciplina(s), embora, legalmente, para atuar nos cursos técnicos, haja exigência da formação pedagógica. Contudo, é permitido o reconhecimento dos saberes profissionais adquiridos no exercício da docência nessa modalidade de ensino há mais de dez anos, no âmbito da Rede Nacional de Certificação Profissional e Formação Inicial e Continuada - Rede CERTIFIC (BRASIL, 2012) e mais recentemente o notório saber instituído pela Lei nº 13.415/2017 que limita sua avaliação e validação ao âmbito restrito da prática do trabalho, dispensando a formação pedagógica.

Pelo que nos indicam os estudos, é inquestionável a importância do conhecimento específico da área disciplinar qualquer que seja o nível de ensino no qual os professores atuam. Entretanto, pela complexidade que é a profissão docente e o contexto peculiar dos IFs dado a singularidade da sua organização curricular e da modalidade de ensino que ofertam, essa formação unidimensional pode não ser suficiente para dar conta do que é perspectivado para o trabalho docente. Nessa direção, no desenvolvimento profissional dos professores tecnólogos-iniciantes, a iniciação na carreira docente extrapolará a 
consolidação da aprendizagem da profissão, a socialização e a apropriação da cultura profissional. Também será espaço de ampliação do conhecimento do campo da educação profissional da qual são egressos, agora não mais na condição de alunos, mas como profissionais do ensino.

\section{Trilhas Metodológicas e Analíticas}

Metodologicamente, optou-se pela pesquisa de abordagem qualitativa do tipo descritiva, considerando-se que esta abordagem possibilita uma imersão no campo de atuação do participante de modo que este expresse suas crenças e concepções, sentidos e significados atribuídos ao seu fazer, no dia a dia da sala de aula. Parte-se do princípio de que: "[...] A abordagem qualitativa defende uma visão holística dos fenômenos, isto é, que leve em conta todos os componentes de uma situação em suas interações e influências recíprocas". (GATTI; ANDRÉ 2010, p. 29-30).

O campo empírico da pesquisa foi o Instituto Federal do Piauí (IFPI) que, além da Reitoria, possui vinte campi em funcionamento distribuídos em dezoito municípios do estado do Piauí. Dentre estes, selecionaram-se quatro campi: Campus Teresina Central, Campus Floriano, Campus Oeiras e Campus Valença. A população investigada foi constituída por tecnólogos-professores que atuam em cursos técnicos e de tecnologia desses campi, cujos critérios de inclusão foram: ser tecnólogo-professor efetivo do IFPI; estar em exercício da docência há até cinco anos; não possuir formação pedagógica e aderir voluntariamente à pesquisa.

Como instrumentos de geração das informações, utilizou-se o questionário e a entrevista no grupo focal. Inicialmente, aplicou-se o questionário, utilizando o formulário eletrônico do Google, para coletar informações para compor o perfil do grupo de interlocutores e conhecer a trajetória do seu desenvolvimento profissional. A entrevista foi semiestruturada, visto que se pretendia conhecer as concepções partilhadas pelos sujeitos da pesquisa, de forma a compreender os elementos que amparam a percepção sobre a docência, a identificação de atividades formativas e a contribuição dos pares e da instituição no desenvolvimento profissional. Escolheu-se o grupo focal por ser uma técnica de entrevista grupal que se caracteriza pelo debate de um tema, em grupo formado para discutir sobre algum assunto, que permite a obtenção de mais de um depoimento ou 
opinião de uma só vez e promove a interação dos pesquisados no processo de coleta de dados (WELLER, 2010).

A partir de dados fornecidos pela Diretoria de Gestão de Pessoas e Procuradoria Institucional, identificou-se 56 tecnólogos-professores de um total de 619 professores ingressantes entre os anos de 2013 e 2018, lotados em catorze Campi do IFPI, sendo, portanto, considerados iniciantes, conforme o marco temporal delimitado por García (1999).

O contato inicial com os potenciais participantes foi mediado pelos diretores de ensino dos campi. Dos 56 tecnólogos-professores abordados, 31 responderam de imediato ao convite. Foram, então, enviados por e-mail pessoal ou institucional o TCLE, para que o assinassem, e o questionário eletrônico para que fosse respondido. Desses, teve-se a devolutiva de 22 questionários. Seguindo as regras defendidas por Gondim (2003), Gatti (2005) e Weller (2010), quanto ao número de participantes do grupo focal, definiu-se que os participantes do grupo focal seriam em número de seis tecnólogos-professores, representando $10 \%$ do universo total desses docentes. Considerando-se a disponibilidade dos participantes que se dispuseram a continuar participando da pesquisa, realizou-se a entrevista no grupo focal no dia 25 de junho de 2019, uma terça-feira, às 9 horas, na sala de videoconferência do Campus Teresina Central, localizado no centro de Teresina. Todos os seis compareceram.

Para garantir o anonimato dos participantes, foram-lhes atribuídos codinomes escolhidos a partir dos sentidos e significados apreendidos de seu discurso e do diálogo destes com as ideias de Freire (2002) sobre os saberes necessários à prática educativa, presentes na obra Pedagogia da Autonomia: saberes necessários à prática educativa. Assim foram nomeados os seis participantes do grupo focal: Entusiasmo, Empatia, Método, Rigorosidade, Exemplo e Confiança. Para o registro da discussão, além da gravação em vídeo, utilizou-se um gravador digital e o registro escrito feito por um colaborador. Posteriormente, esses registros foram transcritos e organizados em duas categorias analíticas definidas com base nas falas obtidas, nas manifestações percebidas e no referencial teórico adotado, conforme apresentados na seção seguinte.

Para organizar as informações produzidas, no campo empírico, recorreu-se a Bardin (2016) e decidiu-se por organizar os dados em duas categorias de análise. Na pré-análise, 
fase da organização propriamente dita, procedeu-se à leitura flutuante das falas transcritas para a aproximação e o levantamento das principais ideias e significados manifestados nas discussões do grupo focal. Em seguida, fez-se a seleção dos temas, norteados pela questãoproblema e objetivos para definir os núcleos de sentido a partir de palavras, frases, afirmações, fragmentos de frase presentes no discurso que possibilitem a compreensão do nosso objeto de estudo. Após, para facilitar a análise, os discursos produzidos foram organizados em duas categorias de análise - Atualização e Relações interativas, a partir da presença ou da ausência de uma característica de conteúdo ou de um conjunto de características, adotando-se os procedimentos da pré-análise. (BARDIN, 2016).

A opção pela $A D$ como técnica de análise das informações produzidas ocorreu em função do diálogo que pode ser estabelecido entre o objeto da pesquisa e essa técnica. Tal como o discurso, as concepções e a aprendizagem dos professores iniciantes sobre a docência são atravessadas pelas crenças, valores e ideologias construídas ao longo do seu processo de escolarização básica e profissional, bem como no exercício da profissão. Segundo afirma Orlandi (2009), o interlocutor, ao tomar a palavra, ao agir discursivamente, revela suas concepções, crenças, valores e visões de mundo, independentemente de sua intencionalidade. Pelo discurso, pode-se apreender os sentidos que os interlocutores atribuem ao tema abordado, compreendendo assim como os elementos mediadores identificados contribuem ou não para o seu desenvolvimento profissional docente.

Deste modo, buscou-se compreender a discursividade do texto produzido pelos interlocutores no encontro do grupo focal, a partir das categorias analíticas da $A D$ Formação Discursiva (FD) e Interdiscursividade, buscando respostas para as inquietações materializadas na questão/problema: Que situações contribuem para o desenvolvimento profissional do tecnólogo-professor em início de carreira? Para tanto, recorremos teoricamente aos autores Maingueneau (1997), Orlandi (2009), Brandão (2012).

Assim como o trabalho, a linguagem também é uma marca distintiva do humano. É por meio dela que estabelecemos relações com o outro, com nós mesmos e com o mundo. Para tanto, é necessário que partilhemos de um sistema de significação que nos permita compreender e atribuir sentidos às manifestações linguísticas. Tomada como fato social e não mais como ato individual, essa perspectiva da linguagem ressalta o papel do interlocutor e do contexto nas produções discursivas. Eis por que Orlandi (2009) afirma que 
os efeitos de sentido produzidos pelo discurso decorrem do duplo jogo que se estabelece entre os sujeitos da interação. Nesse sentido, embora o locutor, ao fazer uso da palavra, tenha uma intencionalidade, um sentido que deseja imprimir a sua fala, o outro do discurso pode interpretá-la atribuindo um sentido diferente do pretendido por aquele, ancorado na imagem que ele tem do falante, do modo como o dito foi dito, do não dito, bem como da condição de interpretação do receptor/alocutário.

É pertinente observar que a $A D$ considera que a linguagem não é transparente, pois "uma mesma palavra, na mesma língua, significa diferentemente, dependendo da posição do sujeito e da inscrição do que diz em uma ou outra formação discursiva" (ORLANDI, 2009, p. 6o) e que o real sentido do discurso encontra-se na sua materialidade linguística e histórica (ORLANDI, 2009). Os sentidos e significados são, pois, produzidos a partir das relações socioculturais e históricas que estabelecemos com o outro. Deste modo, o sentido e o significado da prática docente e os saberes necessários para ensinar dos tecnólogosprofessores estão entrelaçados com sua formação e com os espaços formadores dos quais são egressos, bem como daqueles nos quais atuam e exercem à docência.

Depreende-se pelo exposto que a AD elege como pressupostos basilares de seu aporte teórico os conceitos de ideologia e discurso para a análise dos discursos/textos produzidos pelos homens em situações reais de comunicação/interação (BRANDÃO, 2012). Dadas as características do objeto de estudo e a natureza da pesquisa, assumimos a ideologia como "uma visão, uma concepção de mundo de uma determinada comunidade social numa determinada circunstância histórica" (p. 30), o que nos permitirá compreender como os tecnólogos-professores iniciantes compreendem à docência e articulam os saberes necessários às demandas da prática no exercício da profissão docente na EP.

Já no que se refere ao termo discurso, tendo como base as considerações de Maingueneau (1997) acerca da imprecisão e do caráter polissêmico deste, dar-se-á preferência, pelo termo formação discursiva, que nas palavras de Foucault (2000, p.22), "pode e deve ser dito (articulado sob a forma de alocução, um sermão, um panfleto, uma exposição, um programa, etc.) a partir de uma posição dada em uma conjuntura determinada". Como explica esse autor:

No caso em que se puder descrever, entre um certo número de enunciados, semelhantes sistemas de dispersão, e no caso em que entre os objetos, os tipos de enunciação, os conceitos, as escolhas temáticas, se puder definir 
uma regularidade (uma ordem, correlações, posições e funcionamentos, transformações), diremos, por convenção, que se trata de uma formação discursiva (...) (FOUCAULT, 2000, p. 43, grifo do autor).

Maingueneau (2008), defende o primado do interdiscurso sobre o discurso, considera que o reconhecimento do seu Outro pode circunscrever o dizível de um discurso, pois:

Se, no universo do gramaticalmente dizível, um discurso define uma ilhota de enunciados possíveis considerados capazes de saturar a enunciação a partir de uma posição dada, no conjunto de enunciados assim recusados, ele define igualmente um território como sendo o de seu Outro, daquilo que, mais que qualquer outra coisa, não pode ser dito. O Outro circunscreve justamente o dizível insuportável sobre cujo interdito se constitui o discurso; por conseguinte, não há necessidade de dizer, a cada enunciação, que ele não admite esse Outro, que exclui pelo simples fato de seu próprio dizer. (Maingueneau 2008, p. 37)

Assim, buscar-se-á compreender o desenvolvimento profissional docente pelo discurso dos interlocutores, enunciados do seu lugar social de tecnólogo e de professor em início de carreira na docência, uma vez que a interdiscursividade ocupa um lugar privilegiado no estudo da $A D$ e, acredita-se, permitirá "apreender não uma formação discursiva, mas a interação entre formações discursivas diferentes" (BRANDÃO, 2012, p. 107).

\section{Situações que contribuem para o desenvolvimento profissional do tecnólogo-professor}

Para facilitar a análise dos discursos sobre a percepção que ENTUSIASMO, EMPATIA, MÉTODO, RIGOROSIDADE, EXEMPLO E CONFIANÇA - codinome atribuído aos participantes - têm sobre as situações dos fazeres ou relações de trabalho que contribuem para promover seu desenvolvimento profissional, organizou-se as falas em duas categorias -Atualização e Relações interativas, apresentadas a seguir.

\section{Atualização}

Quando solicitado no grupo focal que apontassem situações que julgassem contribuir para o desenvolvimento profissional, um ponto destacado por RIGOROSIDADE reverberou no discurso dos demais: o encontro pedagógico. De certo modo, foi um estímulo para que percebessem que as atividades da rotina pedagógica, se bem organizadas, podem 
ter também essa finalidade. Eis o que diz a colaboradora: Se minha aula está melhorando, meus alunos estão adquirindo melhores resultados, estou me desenvolvendo profissionalmente. [...] Cursos ou eventos, congressos, workshop, grupo de estudos que vou fazendo, para me atualizar vão me capacitando. [...].

A sequência de sua fala surpreendeu positivamente, pois, como visto, o mais frequente entre os professores não licenciados é investir na pós-graduação stricto sensu. No trecho supracitado, além das situações impulsionadoras do desenvolvimento profissional, é perceptível a crítica feita à forma de realização e organização do encontro pedagógico. A partir da crítica, observa-se que o(a) participante considera essa atividade, em conjunto com as demais indicadas, como uma situação que contribui para o seu crescimento profissional como docente. Outro ponto importante do trecho de fala em análise é a relação que é estabelecida entre o desenvolvimento profissional e a aprendizagem do aluno. Marcelo (2009) afirma que o modelo de desenvolvimento profissional mais impactante na mudança das crenças e atitudes dos professores iniciantes adquiridas ao longo da pré-formação e da formação profissional é o que resulta na melhoria da aprendizagem dos alunos.

Ainda em relação às situações vivenciadas que contribuem para o desenvolvimento profissional, é curioso observar a marcação feita em relação aos cursos, eventos, congressos, workshops e grupos de estudo como investimentos que capacitam e atualizam na área da formação inicial do docente e o encontro pedagógico que prepara para o dia-dia do professor. Não é seguro inferir sobre juízo de valor de um em relação ao outro, mas podemos apontar que a possível distinção seja de conteúdo. É provável que no encontro pedagógico os temas debatidos se limitem às questões normativas/prescritivas do âmbito educacional, administrativo e pedagógico do ensino, das necessidades dos alunos e, nos cursos e demais, aparentemente mais formais/estruturados, dar-se-ia a formação específica.

O trecho de fala da participante ENTUSIASMO pode sustentar nossa inferência de que as temáticas tratadas no encontro pedagógico são focadas nos saberes do conhecimento pedagógico dos professores: No encontro pedagógico trazem pessoas para discussões. Esse ano trouxeram pessoas lá do IFRN para falar sobre o uso de celular, como é que a gente pode trabalhar isso com os alunos em sala. Várias outras coisas, como trabalhar com novas tecnologias [...]. 
O encontro pedagógico é visto por todos os participantes como uma oportunidade de formação que promove o desenvolvimento profissional docente como mostra a fala de CONFIANÇA: [...]. O encontro pedagógico [...] momento de parar para se capacitar. MÉTODO complementa: O encontro pedagógico é um momento de grande importância para a formação e desenvolvimento dos professores. Eu mesmo tinha essa visão de que o encontro pedagógico era bobagem, depois vi a quantidade de coisas que a gente deixa de aprender [...]. Como é possível observar na fala de MÉTODO nem sempre o encontro pedagógico foi compreendido com o sentido de espaço de capacitação. Pode-se dizer que houve um deslocamento do lugar discursivo do sujeito: do olhar de tecnólogo para o olhar de professor. É curiosa, portanto, a mudança de percepção do participante: as suas crenças vão sendo superadas/reelaboradas por meio das experiências que vivenciam no contexto institucional no qual atuam.

EMPATIA também vê o encontro pedagógico como um momento diferenciado que pode proporcionar conhecimentos que ajudem a melhor conduzir a prática docente: "[...] Aprende-se mais sobre a Instituição e une os departamentos e até a Direção [...]". No entanto, sua perspectiva é mais ampla, talvez porque também o perceba sob o viés de coordenadora, lugar que também agora ocupa. Para EMPATIA essa atividade é importante porque aproxima os diversos departamentos, proporcionando um conhecimento mais amplo sobre a instituição. Contudo, a participante a partir do conjunto do olhar de professora e de coordenadora percebeu que a prática docente também é influenciada pelo contexto institucional mais amplo.

Outras atividades formais das rotinas do trabalho docente também foram relacionadas como oportunidade de atualização e de desenvolvimento profissional, como: conselho de classe - reunião do corpo de professores para discussão e reflexão sobre o processo ensino-aprendizagem da turma - assim como momentos informais de encontros sociais e ocasionais entre colegas. EXEMPLO é um dos participantes que aborda a contribuição do conselho de classe e dos momentos informais de interação para o desenvolvimento profissional: [...]Ter um ambiente mais coeso, uma proximidade entre os professores dentro ou fora da instituição, para debater algo diretamente tendo indiretamente um crescimento profissional. [...] Você evoluir profissionalmente não é só título. 
Há um aspecto muito importante acerca do desenvolvimento profissional, destacado por EXEMPLO, que ainda não havia sido abordado pelos demais participantes: a preocupação com o crescimento dos colegas. Essa perspectiva mais ampla sugere que EXEMPLO pode estar em uma fase/etapa da iniciação diferenciada de seus pares, segundo o que inferimos pelo Inventário de Preocupações de García, Mayor Ruiz e Moreno (1995). A suposição sustenta-se pela aproximação do discurso de EXEMPLO com o indicador do inventário citado que diz respeito exatamente à condição do professor se julgar capaz de prestar ajuda aos colegas.

Os discursos dos participantes mostram que ao longo do processo de socialização, de aprendizagem da profissão, o isolamento inicial e o fazer solitário vão cedendo lugar a uma relação de maior proximidade com os pares, proporcionando a aquisição de aprendizagem informal por meio da observação das práticas e discursos desses. Assim, os tecnólogos-professores iniciantes vão revisando e reconstruindo seus saberes sobre a docência. Também é possível observar, pelo discurso de um dos participantes, que, no primeiro ano de docência, a maior proximidade se dá mesmo com os estudantes e que a preocupação com a aprendizagem desses são a motivação para a busca de desenvolvimento profissional, conforme apontou García (2010).

Fiorentini e Crecci (2013) afirmam que a diferença entre formação e desenvolvimento profissional está nas relações que esse estabelece com a prática profissional e o cotidiano escolar/acadêmico. Nesse sentido, o desenvolvimento profissional "tende a ser associado ao processo de constituição do sujeito, dentro de um campo específico. Um processo, portanto, de vir a ser, de transformar-se ao longo do tempo ou a partir de uma ação formativa". (FIORENTINI; CRECCI, 2013, p. 13).

O desenvolvimento profissional tem, pois, característica vivencial e integradora de melhoria das práticas, centra-se no professor e inclui momentos formais e não-formais de ações/atividades com o objetivo de promover melhorias para todos os envolvidos no processo de ensinar-aprender, especialmente, para os alunos e para os próprios professores (OLIVEIRA-FORMOSINHO, 2009).

\section{Relações interativas}


Tardif (2014) afirma que o ensino é uma atividade interativa. García (2010) não só corrobora essa ideia como destaca a importância da interação com os alunos para o desenvolvimento profissional docente. É devido a essa longa interação vivenciada em todo o processo de escolarização e formação profissional que, como visto, os professores não licenciados não questionam estarem ou não preparados para o exercício da docência diante da oportunidade de ingresso na carreira.

Tal como o discurso, os saberes dos professores possuem dimensões exteriores. Sua história de vida, a escolarização, a inserção na instituição escolar, o pertencimento a um grupo de profissionais são (con)formadores do saber docente. O saber do professor é o saber dele (TARDIF, 2014), porém, atravessado por diversos discursos provindos da experiência de vida, da formação e da cultura profissional. Por meio da articulação desses saberes, o professor (re)constrói a concepção sobre o ensino, (re)dimensiona sua prática e se desenvolve profissionalmente como docente. O tecnólogo-professor inscreve-se, deste modo, no entrecruzamento dos discursos dos seus lugares de enunciação de onde elabora suas concepções de educação, de docência e de ensinar-aprender.

Desse modo, as relações interativas contribuem para o desenvolvimento profissional, especialmente dos tecnólogos-professores que se constituem professores no exercício da prática docente. A interação entre os pares é algo desejado por RIGOROSIDADE porque acredita contribuir para o desenvolvimento profissional docente, conforme relata: "O departamento tem que se entrosar. Juntar os professores para elaborar estratégias. O projeto integrador é um momento que o professor desenvolve novas habilidades junto com os colegas e com os alunos [...] O papel do departamento de unir os professores [...] poderia evoluir melhor".

A participante fala de uma experiência que considera possibilitar o aprendizado dos professores, oportunizado pela troca entre os pares e os alunos. Também demonstra clareza quanto a atribuição do departamento e da gestão superior. É possível observar que as práticas pedagógicas institucionais diferem entre os campi e mesmo entre coordenações pertencentes a um mesmo departamento/campus, como evidencia a fala de MÉTODO, que é colega de RIGOROSIDADE, mas lotado em outra coordenação: "[...] Criamos um grupo, um círculo de amizade muito próximo, um ambiente para os professores da nossa área, que está fazendo a diferença. A troca de experiência, todos interagindo, falando de novas 
tecnologias, de um aluno específico, discutindo estratégias. Essa proximidade é importante, sempre tem algo a aprender. Apesar de jovem na docência, tem algo para ensinar para os mais velhos e eles têm muita coisa que pode nos auxiliar".

Note-se como MÉTODO reconhece o potencial dessa interação de promover aprendizagem não só para os iniciantes como também para os veteranos. Mas faz uma ressalva curiosa: "[...] a gente se depara com professores que têm uma cabeça diferente, que dão aula sempre do mesmo jeito e que poderia repassar um conhecimento para quem está iniciando a carreira docente. Tentar extrair o que ele tem de bom para a gente amadurecer. Evitar situações que, às vezes, cometem pelo tempo que estão dando aula, desgostosos da profissão". Mais uma vez aparece no discurso dos participantes a questão da postura adotada quando diante de modelos que consideram contrários a uma prática docente progressista.

As relações interativas com os pares, como vimos, mostram-se oportunidades ricas para promover o desenvolvimento profissional, chegando a se imiscuir nos momentos da vida pessoal dos tecnólogos-professores, como relata CONFIANÇA: "[...] Da nossa base, todo mundo se ajuda. O eixo de agricultura e agropecuária é muito unido. A gente sai do Instituto, mas o Instituto não sai da gente. Vai jantar; está de férias; com outro amigo professor, o assunto é o Instituto".

Pelo que demonstram os discursos dos participantes, à medida que vão acumulando experiências e se apropriando da cultura profissional, vão se aproximando dos pares e estreitando as relações de troca com esses, parecendo ser essa proximidade o ponto de apoio e um dos principais elementos da aprendizagem da profissão, como podemos inferir pelo discurso de EMPATIA: "[...] Mas o que ajuda bastante é a proximidade com os professores. A gente conversa, comenta sobre o aluno, pergunta como é que o outro está fazendo. A forma que uso para melhorar, além de buscar estudar mais [...], para desenvolver melhor minhas aulas, é ver as ideias que meus colegas utilizam[...] Até com os alunos a gente aprende, cresce, evolui".

Apesar de Tardif (2014) referir-se às interações com os alunos como o núcleo do trabalho dos professores, portanto, potencialmente impulsionador do desenvolvimento profissional docente, no discurso de EMPATIA, esse aparece como uma descoberta surpreendente. Inferimos que as práticas pedagógicas e docentes do período de sua 
escolarização e formação profissional a levaram a atribuir papéis bem demarcados ao professor e ao aluno no ato pedagógico: o professor ensina; o aluno aprende. E à medida que vai consolidando suas aprendizagens sobre a docência vai se afastando dessas práticas e elaborando um modo particular de pensar e fazer sua prática docente.

O momento de interação também é uma oportunidade de refletir coletiva e individualmente sobre as práticas, é o que destaca EXEMPLO: "[...] vai fazer festa junina, é um momento diferenciado, uma oportunidade de aproveitar para conversar um pouco, se autoanalisar. [...]". EXEMPLO chama a atenção para a riqueza dos momentos em que estão em interação e acrescenta a autoavaliação que pode redimensionar o processo formativo.

A fala de ENTUSIASMO corrobora o que se afirmou anteriormente sobre a postura adotada pelo professor iniciante frente à conjuntura e organização da prática pedagógica institucional. Diante da impossibilidade de se aproximar dos pares, ENTUSIASMO foca na sua interação com os alunos:" [...] Os professores moram aqui em Teresina. Então, às vezes, mal dá tempo vê-los. Fico no laboratório com os alunos; trabalho em equipe; desenvolvo a proatividade".

A relação com o outro apareceu na fala de todos os participantes e mostrou-se essencial para a consolidação da aprendizagem da docência e da (re)construção da identidade profissional dos tecnólogos-professores. Também ficou evidenciado que as características pessoais e estruturais influenciam as posturas adotadas frente aos desafios e às práticas profissionais vigentes no espaço institucional.

\section{Considerações Finais}

O diálogo entre o referencial teórico e metodológico presentes na análise dos discursos dos participantes da pesquisa permitiu responder à questão norteadora: Que situações contribuem para o desenvolvimento profissional do tecnólogo-professor? O que nos autoriza a afirmar que nosso objetivo - Analisar as situações que contribuem para o desenvolvimento profissional do tecnólogo-professor em início de carreira - foi alcançado. Ao fim da análise das diferentes manifestações discursivas, os dados produzidos nos permitiram inferir que: 
- A relação com os pares e o apoio institucional, no início da docência, é quase inexistente, provocando nos tecnólogos-professores sentimentos de solidão e isolamento. Deste modo, a docência é desempenhada tendo apenas os alunos como testemunhas do fazer pedagógico;

- Diferentemente dos resultados das pesquisas envolvendo professores da educação básica e bacharéis que atuam na educação superior, os tecnólogos-professores, à medida que se socializam, buscam ajuda com os pares e demais setores oferecidos pela instituição;

- Os tecnólogos-professores, após o confronto com as dificuldades da prática, valorizam o conhecimento pedagógico e buscam a autoformação por meio de leituras e da aprendizagem informal, a partir da observação das práticas dos colegas; valorizam os saberes disciplinares, no entanto, compreendem que a docência também comporta uma dimensão afetiva e um compromisso com a formação integral do aluno, para além da dimensão técnica;

- O encontro pedagógico e outros momentos formais e/ou informais são considerados pelos tecnólogos-professores oportunidades de aprendizagem e desenvolvimento profissional. Deste modo, estão abertos à participação em cursos e/ou programas de formação e reivindicam a criação de espaços formativos, bem como, maior apoio da gestão em seu processo de desenvolvimento profissional.

Face ao que foi dito até aqui, pode-se afirmar que a interação com os pares e com os alunos e a experiência da prática docente são elementos articuladores dos saberes pedagógicos e da (re)significação da docência. Foi possível, também, inferir pelos discursos que a prática é formadora; que nessa formação discursiva, de onde se enunciam os tecnólogos-professores, esses, inicialmente, constroem seus discursos sobre educação/pedagogia a partir das crenças adquiridas ao longo da formação, aspecto que, considerando o conceito de formação discursiva e o papel do interdiscurso, permite afirmar que o lugar de fala do tecnólogo-professor não é o mesmo do professor licenciado. No entanto, à medida que vão ganhando experiência, refletem sobre essa, e passam a (re)construir seus discursos e práticas com mais autonomia em função do feedback dos alunos ou da observação das práticas dos pares mais experientes. Em relação a esses, também é oportuno destacar que mesmo aqueles de práticas mais tradicionais também contribuem para o desenvolvimento profissional dos tecnólogos-professores em início de 
carreira, porque representam modelos dos quais querem se afastar, obrigando-os a pensarem e buscarem outras práticas mais condizentes com suas concepções de ensino.

Por fim, ressalta-se que a pesquisa proporcionou, por meio da interação promovida na entrevista no grupo focal, o crescimento tanto da pesquisadora quanto dos participantes. A técnica se mostrou produtiva e adequada, pois proporcionou o encontro de sujeitos que vivenciam as mesmas dificuldades, a exteriorização e a valorização de suas experiências e a troca entre os pares. Ademais, destaca-se a importância da criação de um espaço permanente de formação continuada que potencialize o encontro entre os diversos grupos de professores e profissionais frente às necessidades de formação e dificuldades enfrentadas no contexto da sala de aula, dimensões que atravessaram esta pesquisa.

\section{Referências bibliográficas}

BARDIN, L. Análise de conteúdo. Trad. Luís Antero Reto. São Paulo: Edições 70, 2016.

BRANDÃO, H. H. N. Introdução à análise do discurso. 3. ed. Campinas, SP: Editora da Unicamp, 2012.

BRASIL. Ministério da Educação. Resolução CNE/CEB nº o6, de 20 de setembro de 2012. Define Diretrizes Curriculares Nacionais para a Educação Profissional Técnica de Nível Médio. Disponível em:

http://portal.mec.gov.br/index.php?option=com_docman\&view=download\&alias=11663rceboo6-12-pdf\&category_slug=setembro-2012-pdf\&ltemid=30192. Acesso em: 13 set. 2018.

CUNHA, M. I. da. Lugares de formação: tensões entre a academia e o trabalho docente. In: DALBEN, Ângela Imaculada Loureiro de Freitas et al (org.). Convergências e tensões no campo da formação e do trabalho docente. Belo Horizonte: Autêntica, 2010, p. 129-149. Disponível em: http://www.fae.ufmg.br/endipe/livros/Livro_4.PDF. Acesso em: Acesso em: 20 mar. 2018.

CUNHA, M. I. da; ZANCHET, B. M. B. A. A problemática dos professores iniciantes: tendência e prática investigativa no espaço universitário. Educação, Porto Alegre, v. 33, n. 3, p. 189-197, set./dez., 2010. Disponível em:

http://revistaseletronicas.pucrs.br/ojs/index.php/faced/article/viewFile/6999/5717. Acesso em: 11 jun. 2018.

FIORENTINI, D.; CRECCI, V. Desenvolvimento Profissional DOCENTE: Um Termo GuardaChuva ou um novo sentido à formação? Revista Brasileira de Pesquisa sobre Formação Docente, Belo Horizonte, v. 5, n. 8, p. 11-23, jan./jun. 2013. Disponível em: https://revformacaodocente.com.br/index.php/rbpfp/article/view/74. Acesso em: 4 mar. de 2018. 
FOUCAULT, Michel. A arqueologia do saber. 6.ed. tradução de Luiz Felipe Baeta Neves. 6.ed. Rio de Janeiro: Forense Universitária, 2000, 239p.

FREIRE, Paulo. Pedagogia da autonomia: saberes necessários à prática docente. São Paulo: Paz e Terra, 2002.

GARCÍA, C. M. Formação de professores: para uma mudança educativa. Portugal: Porto Editora, 1999.

GARCÍA, C. M. O professor iniciante, a prática pedagógica e o sentido da experiência.

Revista Brasileira de Pesquisa sobre Formação Docente, Belo Horizonte, v. 01, n. 03, p.11 -49, ago./dez. 2010. Disponível em: http://formacaodocente.autenticaeditora.com.br. Acesso em: 1 jul. 2018.

GARCÍA, C. M.; MAYOR RUIZ, C.; MORENO, M. S. Un instrumento para evaluar cambios en las etapas de preocupaciones de profesores: el inventario de preocupaciones de profesores. Enseñanza, Logrono, v. 1, n. 13 p. 153-178, 1995. Disponível em: dialnet.unirioja.es/servlet/articulo?codigo=95705. Acesso em: 30 jun. 2018.

GATTI, B. A. Grupo focal na pesquisa nas Ciências Sociais e Humanas. Brasília: Líber Livro, 2005 .

GATTI, B. A.; ANDRÉ, M. E. D. de A. A relevância dos métodos de pesquisa qualitativa em Educação no Brasil. In: WELLER, W.; PFAFF, N. (Orgs.). Metodologias da Pesquisa Qualitativa em Educação: teoria e prática. Petrópolis, RJ: 2010. p. 29-38.

GONDIM, S. M. G. Grupos focais como técnica de investigação qualitativa: desafios metodológicos. Paideia, Ribeirão Preto, v. 12, n. 24, p. 149-161, out. 2003. Disponível em: http://www.scielo.br/pdf/paideia/v12n24/o4.pdf. Acesso em: 11 out. 2018.

GUARNIERE, M. R. O início na carreira docente. In: GUARNIERE, M. R. (org.). Aprendendo a ensinar: o caminho nada suave da docência. 2. ed. Campinas: Autores Associados, 2005. p. 5-24.

MAINGUENEAU, D. Gênese dos discursos. São Paulo Parábola Editorial, 2008.

. Novas tendências em análise do discurso. Trad. Fredalndursky. 3. ed. Campinas, SP: Pontes: Editora da Universidade Estadual de Campinas, 1997.

MARCELO, C. Desenvolvimento Profissional Docente: passado e futuro. Sísifo: Revista de Ciência da Educação, Feira de Santana, v. 1, n. 8, p. 7-22, jan./abr., 2009. Disponível em: http://www.unitau.br/files/arquivos/category_1/MARCELO__Desenvolvimento_Profission al_Docente_passado_e_futuro_1386180263.pdf. Acesso em: 01 jul. 2018

MARCELO, C.; VAILLANT, D. Desarrolloprofesional docente ¿ Cómo se aprende a enseñar? Madrid: Narcea, s/d. E-book. ISBN: 9788427717701. 
NONO, M. A. Professores iniciantes: o papel da escola em sua formação. Porto Alegre: Mediação, 2011.

NONO, M. A.; MIZUKAMI, M. G. N. Processos de formação de professoras iniciantes. Revista Brasileira de Estudos Pedagógicos, São Paulo, v. 87, n. 217, p. 382-400, set./dez. 2006. Disponível em: http://rbep.inep.gov.br/index.php/rbep/article/view/812/787. Acesso em: 21 jul. 2018.

NÓVOA, A. Desafios do trabalho do professor no mundo contemporâneo. São Paulo: SINPRO, 2007.

OLIVEIRA-FORMOSINHO, J. Desenvolvimento profissional dos professores. In:

FORMOSINHO, J. (coord.) Formação de professores: aprendizagem profissional e acção docente. Porto, Portugal: Porto Editora, 2009. p. 221-284.

ORLANDI, E. P. Análise de discurso: princípios e procedimentos. 8. ed. Campinas, SP: Pontes, 2009.

ROMANOWSKI, J. P.; MARTINS, P. L. O. Desafios da formação de professores iniciantes. Páginas de Educación, v. 6, n. 1, p. 83-96, 2013. Disponível em:

https://dialnet.unirioja.es/ejemplar/507245. Acesso em: 11 out. 2018.

TARDIF, M. Saberes docentes e formação profissional. 17. ed. Petropólis, RJ: Vozes, 2014

WELLER, W. Grupos de discussão: aportes teóricos e metodológicos. In: WELLER, W.; PFAFF, N. (org.). Metodologias da pesquisa qualitativa em Educação: teoria e prática. Petrópolis: Vozes, 2010. p. 54-66.

\footnotetext{
' Mestra em Educação e Especialista em Avaliação Educacional. Pedagoga do Instituto Federal do Piauí-IFPI. Email: landradepio@gmail.com.

ii Doutora em Educação, Professora e Coordenadora do Programa de Pós-Graduação em Educação da Universidade Federal do Piauí-UFPI. E-mail: glorinha_m@yahoo.com.br.
} 